\title{
Epileptogenic potential of mefloquine chemoprophylaxis: a pathogenic hypothesis Remington L Nevin
}

Address: United States Africa Command, Combined Joint Task Force Horn of Africa, Camp Lemonier, FPO AE 09363, Republic of Djibouti Email: Remington L Nevin - remington.nevin@us.army.mil

Published: 5 August 2009

Malaria Journal 2009, 8: 188 doi:10.1 I86/|475-2875-8-188

This article is available from: http://www.malariajournal.com/content/8////88

(c) 2009 Nevin; licensee BioMed Central Ltd.

This is an Open Access article distributed under the terms of the Creative Commons Attribution License (http://creativecommons.org/licenses/by/2.0), which permits unrestricted use, distribution, and reproduction in any medium, provided the original work is properly cited.
Received: 17 April 2009

Accepted: 5 August 2009

\begin{abstract}
Background: Mefloquine has historically been considered safe and well-tolerated for long-term malaria chemoprophylaxis, but prescribing it requires careful attention in order to rule out contraindications to its use. Contraindications include a history of certain neurological conditions that might increase the risk of seizure and other adverse events. The precise pathophysiological mechanism by which mefloquine might predispose those with such a history to seizure remains unclear.

Presentation of the hypothesis: Studies have demonstrated that mefloquine at doses consistent with chemoprophylaxis accumulates at high levels in brain tissue, which results in altered neuronal calcium homeostasis, altered gap-junction functioning, and contributes to neuronal cell death. This paper reviews the scientific evidence associating mefloquine with alterations in neuronal function, and it suggests the novel hypothesis that among those with the prevalent EPMI mutation, inherited and mefloquine-induced impairments in neuronal physiologic safeguards might increase risk of GABAergic seizure during mefloquine chemoprophylaxis.

Testing and implications of the hypothesis: Consistent with case reports of tonic-clonic seizures occurring during mefloquine chemoprophylaxis among those with family histories of epilepsy, it is proposed here that a new contraindication to mefloquine use be recognized for people with EPMI mutation and for those with a personal history of myoclonus or ataxia, or a family history of degenerative neurologic disorder consistent with EPMI. Recommendations and directions for future research are presented.
\end{abstract}

\section{Background}

Mefloquine $\left(\right.$ Lariam $\left.^{\oplus}\right)$ is a commonly prescribed antimalarial. Although historically the long-term use of mefloquine for malaria chemoprophylaxis has been considered safe and well-tolerated [1,2], careful prescribing is needed to minimize the potential for severe neurological adverse events, including myoclonus and seizure, for which individuals with certain neurological histories appear to be at highest risk [3]. In particular, case-report [4], case-series [5], and retrospective cohort [6,7] studies define a well-characterized pattern of increased susceptibility to seizure and other movement disorders including nystagmus and ataxia [4] with use of mefloquine among those with a personal [4-6] or family history [7] of such conditions. Additional case-reports describe, in the absence of personal or family history, the occurrence of multifocal myoclonus [8], convulsions, and seizures following both therapeutic [9] and prophylactic doses [1012] when mefloquine is co-administered with other medications such as fluroquinolones [13], or occasionally 
when mefloquine administration is preceded by non-specific neurologic prodrome [14].

The U.S. package insert cautions that mefloquine "should not be prescribed for prophylaxis in patients with active depression, a recent history of depression, generalized anxiety disorder, psychosis, or schizophrenia or other major psychiatric disorders, or with a history of convulsions" [15]. The prevalence of these contraindications is approximately $9-10 \%$ in both military [16] and civilian [17] populations that present for malaria chemoprophylaxis, which underscores that clinicians must exercise significant care prior to prescribing and dispensing mefloquine.

A growing body of recent evidence from in vitro and in vivo studies in animal models characterize the direct neurotoxic effects of mefloquine [18-22], the ability of mefloquine to disrupt normal neuronal calcium homeostasis $[21,23,24]$, as well as cellular calcium homeostasis [25], and mefloquine's inhibition of normal gap-junction function [26-28]. Many of these results are readily demonstrated at concentrations consistent with chemoprophylaxis $[21,22,26]$. Despite these advances in understanding, the precise pathophysiological mechanism remains unclear by which mefloquine predisposes to seizure people with a personal or family history of certain neurological conditions [3].

A satisfying explanation for the pathogenic mechanism of mefloquine-induced epileptogenesis would integrate current knowledge of mefloquine neurotoxicity with an understanding of the pathogenic mechanism underlying clinical conditions that mirror the clinical presentation of mefloquine-associated seizure. Furthermore, such an explanation would elucidate why these reactions occur in specific populations. This opinion paper reviews recent research and presents a novel hypothesis, consistent with these axioms, that offers an explanation for why mefloquine may predispose to seizure certain individuals with EPM1 genotype.

\section{Presentation of the hypothesis Mefloquine accumulates at high concentrations in brain tissue}

Mefloquine is a highly lipotropic drug which readily crosses the blood-brain barrier $[29,30]$ and whose efflux from neuronal tissues is mediated by the efflux pump Pglycoprotein (P-gp) [29,31]. In rat models a neuronal accumulation of enantiomeric mefloquine supports a stereoselective active neuronal efflux, and in in vivo mouse models, the neuronal concentration of quinine is raised in the presence of mefloquine [32]. Mefloquine is, therefore, both a substrate and an inhibitor of P-gp [31,33].
Under conditions of long-term chemoprophylaxis, mefloquine levels in plasma have been reported between 1.5 and $3.3 \mu \mathrm{M}$ [34], but relatively few post-mortem studies have defined concentrations in brain tissue under conditions of chemoprophylaxis. One post-mortem case-series identified mefloquine in brain tissue at concentrations between 8.7 and $14 \mathrm{mg} / \mathrm{kg}$ [35], corresponding to significantly higher molar concentrations of between 21 and 34 $\mu \mathrm{M}$. Another post-mortem study demonstrated ratios of brain white matter to serum mefloquine of 22.9:1 and 55.5:1 for (-) and (+) enantiomeric mefloquine, respectively [30]. This same study found grey matter concentrations were approximately $69 \%$ of that found in white matter [30]. Based on these data it is reasonable to conclude that mefloquine typically accumulates in brain tissue at concentrations approximately 10-30 times higher than found in serum [21].

The MDR1 gene codes for P-gp. Research postulates that polymorphisms in the MDR1 gene that result in a reduced expression of P-gp will result in lower mefloquine efflux from the brain and lead to higher brain tissue concentrations [33] than in individuals lacking these polymorphisms. Studies have demonstrated that the neuropsychiatric effects of mefloquine, as identified by earlier cohort studies [36], are more common among those with MDR1 polymorphisms [33]. It is therefore plausible that common MDR1 polymorphisms, by significantly raising neuronal levels of mefloquine, might mediate the propensity towards dose-dependent adverse events.

\section{Mefloquine interferes with normal gap junction functioning}

Mefloquine exhibits a potent dose-dependent ability to interfere with the functioning of gap junctions, which are inter-neuronal channels created by distinct oligomeric proteins called connexins [37]. A variety of connexin (Cx) proteins have been identified and characterized, identified by their molecular weight [37]. Of these, Cx36 and $\mathrm{Cx} 43$ are widely distributed in neuronal tissue and show sensitivity to mefloquine.

Gap junctions formed by $\mathrm{Cx} 36$ predominate in neurons [38] in rat models, and play a critical role in the direct transport of ions between adjacent neurons, a process known as neuronal coupling [39]. Cx36 is found at high concentrations within the inhibitory GABAergic interneurons of the cortical striatum [39]. In mouse and rat models, Cx36 is also found throughout the ventral tegmental area [40], the neocortex [26], thalamic reticular nucleus [26], inferior olive $[38,41]$, and possibly hippocampus [26]. 
Lack of functioning Cx36 has been implicated in epileptogenesis [42], although the underlying mechanism is not clear. In mice lacking Cx36, deficits are found in synchronous firing within cortical, thalamic, and brainstem circuits [26]. Gene-transfer research demonstrates inactivation of $\mathrm{Cx} 36$ in mature rat models results in measurable degradation in fine temporal coordination of muscle firing [41]. Mefloquine blockade of Cx36 also suppresses essential tremor when induced in mouse models [28]. At high concentrations, mefloquine also decreases the amplitude of Cx36-mediated cortical spreading depression in rat models in vitro [27].

Significant physiological effects due to mefloquine are noted at concentrations consistent with chemoprophylaxis. At concentrations of $25 \mu \mathrm{M}$, mefloquine inhibition of Cx36 in in vivo mouse models is associated with a decrease in GABAergic spontaneous synaptic currents to motor neurons [39]. In in vitro studies, mefloquine at concentrations as low as $10 \mu \mathrm{M}$ significantly reduced cortical coupling, and at $25 \mu \mathrm{M}$ mefloquine caused increases in spontaneous chemical synaptic activity [26]. In in invo studies in rats, mefloquine at concentrations of $25 \mu \mathrm{M}$ antagonized the stimulatory action of modafinil, likely through decreased gap junction-mediated electrical coupling [43].

The predominant connexin expressed in neuronal glial tissue is $\mathrm{Cx} 43$, which is thought to permit the transfer of small molecular weight molecules critical to maintenance of cellular homeostasis [37]. Functioning gap junctions in the astrocyte network serves to dilute substances cleared from the extracellular environment, including free calcium [37]. At levels of $30 \mu \mathrm{M}$, mefloquine strongly inhibits Cx43 [26].

\section{Mefloquine disrupts intracellular calcium homeostasis}

Mefloquine in vitro also strongly interferes with neuronal calcium homeostasis, likely through inhibitory action on the endoplasmic reticulum (ER) calcium ATPase, leading to the intracellular release of the ER calcium stores [21]. These effects have been consistently noted in rat neurons in vitro at concentrations of between $10-30 \mu \mathrm{M}[21,22]$. In a dog model, mefloquine inhibits inositol-1,4,5-phosphate (IP3)-mediated calcium release from neuronal microsome stores, although at slightly higher molar concentrations [24], suggesting a role for mefloquine in IP3receptor (IP3-R)-mediated signal transduction processes.

\section{Mefloquine produces dose-dependent neuronal toxicity}

In rat model experiments, mefloquine produces permanent and dose-dependent brain stem lesions in the nucleus gracilis, nuclear cuneatus, and solitary tract [20]. These lesions were accompanied by dose-dependent impairments in motor performance consistent with loss of vestibular or nucleus gracilis-dependent proprioceptive function. Inhibition of cytoplasmic calcium homeostasis might trigger a shutdown of protein synthesis [23], resulting in an induction of proapoptotic mediators and contributing to the drug's neurotoxic effects [21]. Such lesions were moderately demonstrated at doses of $187 \mathrm{mg} / \mathrm{kg}$, corresponding with rat plasma concentrations of $2.1 \mu \mathrm{g} /$ $\mathrm{mL}$ [20] or approximately $5.6 \mu \mathrm{M}$ plasma concentration.

\section{Significance of EPMI mutation}

Unverricht-Lundborg Disease (ULD) is an inheritable, autosomal recessive, degenerative form of epilepsy characterized as progressive and myoclonic, type 1 (EPM1) [44]. ULD is generally diagnosed prior to age 18 , and in half of cases the first presentation is tonic-clonic seizure [44]. EPM1 homozygosity is characterized by the early onset of progressive ataxia, incoordination, intentional tremor and dysarthria.

Genetic studies have revealed that EPM1 is associated with loss of function in the cystatin B gene (CSTB) in over $90 \%$ of cases [45] due to a dodecamer repeat expansion in the CSTB promoter [45] that results in significant downregulation of mRNA expression. CSTB protects against the proteolytic activity of cathepsin cystein proteases, particularly capthepsin B [45], and the main function of cytosolic CSTB in normal physiology is thought to be protection from lysosomal protease leakage [46]. However, in CSTB knock-out mice, ataxia, myoclonic seizures, rapid cerebellar degeneration and apoptosis are noted [47] and are associated with significant increases in transcription of cathepsin S and markers of glial activation [48], themselves consistent with reactive changes suggestive of widespread cortical and subcortical grey matter damage [49]. CSTB knock-out mice also demonstrate increased susceptibility in vivo to severe seizure, including generalized tonic-clonic seizures, and in vitro exhibit neuronal hyperexcitability characterized by decreased seizure threshold [50].

Additionally, mouse studies demonstrate that EPM1 heterozygosity results in lower cystatin B expression than wild-type mice and is associated also with near-universal mild neurogeneration and neuronal atrophy [51]. In some cases heterozygosity also might be associated with mild signs and symptoms of ULD, including ataxia, motor incoordination and myoclonus [51].

These results suggests that CSTB deficiency creates impairments in the normal spectrum of neuronal physiologic safeguards, which predisposes EPM1 heterozygotes to neuronal hyperexcitability and hastens neuronal cell death with seizure [50]. 


\section{Epileptogenic potential of mefloquine in EPMI heterozygotes}

Despite the absence in the literature of such events being reported, and based solely on biologic plausibility, the previous findings support the novel hypothesis that EPM1 heterozygosity might substantially increase the risk of seizure among subjects exposed to mefloquine, particularly in the presence of an MDR1 polymorphism or other condition, including the co-administration of a P-gp inhibitory drug that raises brain concentrations of mefloquine.

Among people with EPM1 mutation and exposed to mefloquine at an as-yet undetermined threshold greymatter concentration, inherited predisposition to and reductions in physiologic protection from apoptosis are postulated to be exacerbated by a mefloquine-induced dysfunction among a spectrum of ordinarily complementary neuronal physiologic safeguards that become altered in mefloquine's presence. These altered physiologic safeguards include a loss of normal neuronal calcium homeostasis via mefloquine-induced release of ER calcium stores, altered glial cell function via mefloquine-induced Cx43-mediated gap junction dysfunction; and decreased GABAergic cortical inhibition and coupling and increased motor-neuron synaptic activity via mefloquine-induced Cx36-mediated gap junction dysfunction.

Although the precise role of altered astrocyte gap function in mediating apoptosis is not yet clear [52], it might be that in the presence of mefloquine-induced $\mathrm{Cx} 43$ dysfunction, increased neuronal cellular calcium resulting from inhibition of ER calcium ATPase is mediated less effectively by the astrocyte network, which then more readily induces neuronal proapoptotic mechanisms themselves promoted by mefloquine.

Simultaneously, it might be that mefloquine-induced Cx36 dysfunction results in decreased inhibitory GABAergic input and increased spontaneous synaptic activity. Supporting this postulate are results from in vivo mouse models, which demonstrate that high-dose mefloquine induces seizure, and that this effect is blocked by potent GABA agonists [53].

Given the simultaneous loss of multiple neuroprotective safeguards associated with mefloquine administration, it is, therefore, plausible that the first manifestation of seizure in EPM1 heterozygotes might occur with mefloquine prophylaxis.

\section{Implications and testing of the hypothesis}

Consistent with case reports of tonic-clonic seizures occurring during mefloquine chemoprophylaxis among those with family histories of epilepsy [7], out of an abundance of caution and based on biological plausibility, consideration should be given to a contraindication to mefloquine use among those with EPM1 mutation; or absent formal genetic diagnosis, among those with a personal or family history of seizure, myoclonus, ataxia, or degenerative neurologic disorder consistent with EPM1. Such a contraindication would expand upon and clarify existing U.S. package-insert guidance that limits existing neurologic contraindications to a personal "history of convulsions. "

The prevalence of EPM1 homozygosity is as high as four per 100,000 in some western populations [44], which suggests that the genotypic frequency of EPM1 heterozygosity under Hardy-Weinberg equilibrium could exceed one percent. Such underlying prevalence might be consistent with the incidence of observed neurologic adverse events with mefloquine prophylaxis, particularly when coupled with an as-yet-unclear population prevalence of either MDR1 polymorphisms, co-administration of medication which may further inhibit P-gp function, or other conditions such as liver dysfunction which may decrease metabolism and, therefore, lead to increases in neuronal mefloquine concentrations.

Post-marketing studies, including genetic studies testing for EPM1 mutation among people who have suffered severe seizures following the prophylactic or therapeutic use of mefloquine should be conducted to further elucidate this alleged risk. Additionally, post-mortem studies should be conducted also to better characterize the correlations between brain concentrations of mefloquine, prevalent genetic mutations including EPM1 and MDR-1, co-morbid liver dysfunction including alcohol- and druginduced impairments, and the extent of neuronal apoptosis that occur under conditions of chemoprophylaxis.

Although obtaining access to large numbers of post-mortem specimens exposed to mefloquine chemoprophylaxis has proven challenging historically, ongoing U.S. military efforts in malarious areas, including Afghanistan, Africa, Asia, and South America, present an unfortunate but meaningful opportunity to improve understanding in this area. Because mefloquine has until recently served as primary chemoprophylaxis for U.S. service members deployed to some of these areas, [16], and may still be used by a significant proportion of the U.S. military population [54], the direct measurement of brain mefloquine concentrations [35] and the extent of neuronal apoptosis during U.S. military-directed post-mortem examination, would assist greatly in improving understanding of these and other recently postulated mechanisms of mefloquine neurotoxicity [55]. 


\section{Abbreviations}

ATP: Adenosine Triphosphate; CSTB: Cystatin B; Cx: Connexin; EPM1: Progressive Myoclonic Epilepsy; Type 1; ER: Endoplasmic Reticulum; GABA: Gamma Aminobutyric Acid; IP3: Inositol-1,4,5-Phosphat; IP3-R: IP3 Receptor; $\mathrm{M}$ : Micro Molar; ug/mL: Microgram per Militer; $\mathrm{mg} / \mathrm{kg}$ : Miligrams per Kilogram; MDR1: Multi-Drug Resistance 1 Gene; P-gp: P-Glycoprotein; ULD:Unverricht-Lundborg Disease; U.S.: United States.

\section{Competing interests}

The author declares that he has no competing interests.

\section{Disclaimer}

The opinions expressed are those of the author and do not necessarily reflect those of the Department of the Army, the Combined Joint Task Force Horn of Africa, the United States Africa Command, or the Department of Defense. The author wrote this paper as part of his routine activities and no external support or funding was obtained.

\section{Acknowledgements}

The author thanks Dr. (Colonel) Jeffrey J. Johnson for his support during the initial stages of this investigation, and Ms. Catherine K. Craven, MLS, MA for her assistance in the preparation and review of this manuscript.

\section{References}

I. Wells TS, Smith TC, Smith B, Wang LZ, Hansen CJ, Reed RJ, Goldfinger WE, Corbeil TE, Spooner CN, Ryan MAK: Mefloquine use and hospitalizations among US service members, 2002-2004. Am J Trop Med Hyg 2006, 74:744-749.

2. Chen LH, Wilson ME, Schlagenhaug P: Prevention of malaria in long-term travelers. JAMA 2006, 296:2234-2244.

3. Chen LH, Wilson ME, Schlagenhauf P: Controversies and misconceptions in malaria chemoprophylaxis for travelers. JAMA 2007, 297:225I-2263.

4. Manto MU: Episodic see-saw nystagmus in spino-cerebellar ataxia type 2 (SCA-2). Cerebellum 2002, 1:91-92.

5. Bem JL, Kerr L, Stürchler D: Mefloquine prophylaxis: an overview of spontaneous reports of severe psychiatric reactions and convulsions. J Trop Med Hyg 1992, 95:167-179.

6. Steffen R, Fuchs E, Schildknecht J, Naef U, Funk M, Schlagenhauf $P$, Phillips-Howard P, Nevill C, Stürchler D: Mefloquine compared with other malaria chemoprophylactic regimens in tourists visiting East Africa. Lancet 1993, 34 I: I 299-1303.

7. Barrett PJ, Emmins PD, Clarke PD, Bradley DJ: Comparison of adverse events associated with use of mefloquine and combination of chloroquine and proguanil as antimalarial prophylaxis: postal and telephone survey of travelers. BMJ 1996, 313:525-528.

8. Jiménez-Huete A, Gil-Nagel A, Franch O: Multifocal myoclonus associated with mefloquine chemoprophylaxis. Clin Neuropharmacol 2002, 25:243.

9. Schiemann R, Coulaud JP, Bouchaud O: Seizures after antimalarial medication in previously healthy persons. J Travel Med 2000, 7:155-156.

10. Pous E, Gascón J, Obach J, Corachan M: Mefloquine-induced grand mal seizure during malaria chemoprophylaxis in a non-epileptic subject. Trans R Soc Trop Med Hyg 1995, 89:434.

II. Singh K, Shanks GD, Wilde H: Seizures after mefloquine. Ann Intern Med I 99|, I | 4:994.

12. Ruff TA, Sherwen SJ, Donnan GA: Seizure associated with mefloquine for malaria prophylaxis. Med J Aust 1994, 161:453.

13. Mangalvedhekar SS, Gogtay NJ, Wagh VR, Waran MS, Mane D, Kshirsagar NA: Convulsions in non-epileptics due to mefloquine-fluoroquinolone co-administration. Natl Med J India 2000, 13:47.
14. Meyer P, Combes N, Corne P, Jonquet O: [Convulsions and shock during antimalarial chemoprophylaxis with mefloquine]. Presse Med 2003, 32:408.

15. Roche Laboratories Inc: Lariam $®$ (mefloquine hydrochloride) Complete Product Information Nutley, NJ; 2008.

16. Nevin RL, Pietrusiak PP, Caci JB: Prevalence of contraindications to mefloquine among USA military personnel deployed to Afghanistan. Malar J 2008, 7:30.

17. Hill DR: Pre-travel health, immunization status, and demographics of travel to the developing world for individuals visiting a travel medicine service. Am J Trop Med Hyg I991, 45:263-270.

18. Ding D, Weidong $Q$, Jiang H, Salvi R: Mefloquine-induced apoptosis in hair cells and spiral ganglion neurons in cochlear organotypic cultures. Association for Research in Otolaryngology Meeting, II February 2007, Poster Session D5 [http://www.aro.org/archives/ 2007/2007 6II.html].

19. Jiang $H$, Ding $D$, Salvi R: Mefloquine-induced changes in apoptotic gene expression in cochlear basilar membrane and spiral ganglion neurons. Association for Research in Otolaryngology Meeting, 17 February 2008, Poster Session DII [http://www.aro.org/ archives/2008/2008 327 2cdaac2d.html]

20. Dow G, Bauman R, Caridha D, Cabezas M, Du F, Gomez-Lobo R, Park M, Smith K: Mefloquine induces dose-related neurological effects in a rat model. Antimicrob Agents Chemother 2006, 50:1045-1053.

21. Dow GS, Hudson TH, Vahey M, Koenig ML: The acute neurotoxicity of mefloquine may be mediated through a disruption of calcium homeostasis and ER function in vitro. Malar J 2003, 2:14.

22. Dow GS, Heady TN, Bhattacharjee AK, Caridha D, Gerena L, Gettayacamin M, Lanteri CA, Obaldia N 3rd, Roncal N, Shearer T, Smith PL, Tungtaeng A, Wolf L, Cabezas M, Yourick D, Smith KS: Utility of alkylaminoquinolinyl methanols as new antimalarial drugs. Antimicrob Agents Chemother 2006, 50:4132-4I43.

23. Dow GS, Caridha D, Goldberg M, Wolf L, Koenig ML, Yourick DL, Wang Z: Transcriptional profiling of mefloquine-induced disruption of calcium homeostasis in neurons in vitro. Genomics 2005, 86:539-550.

24. Lee HS, Go ML: Effects of mefloquine on Ca2+ uptake and release by dog brain microsomes. Arch Int Pharmacodyn Ther 1996, 33 I:22I-23I.

25. Toovey S, Bustamante LY, Uhlemann AC, East JM, Krishna S: Effect of artemisinins and amino alcohol partner antimalarials on mammalian sarcoendoplasmic reticulum calcium adenosine triphosphatase activity. Basic Clin Pharmacol Toxicol 2008, 103:209-13.

26. Cruikshank SJ, Hopperstad M, Younger M, Connors BW, Spray DC, Srinivas M: Potent block of $\mathrm{C} \times 36$ and $\mathrm{Cx} 50$ gap junction channels by mefloquine. Proc Natl Acad Sci USA 2004, 101:|2364-I2369.

27. Margineanu DG, Klitgaard H: The connexin 36 blockers quinine, quinidine and mefloquine inhibit cortical spreading depression in a rat neocortical slice model in vitro. Brain Res Bull 2006, 7I:23-28.

28. Martin FC, Handforth A: Carbenoxolone and mefloquine suppress tremor in the harmaline mouse model of essential tremor. Mov Disord 2006, 21:1641-1649.

29. Barraud de Lagerie S, Comets E, Gautrand C, Fernandez C, Auchere $D$, Singlas E, Mentre F, Gimenez F: Cerebral uptake of mefloquine enantiomers with and without the P-gp inhibitor elacridar (GF I 2 I09 I 8) in mice. Br J Pharmacol 2004, I 4 I: I 2 I 4- I 222.

30. Pham YT, Nosten F, Farinotti R, White NJ, Gimenez F: Cerebral uptake of mefloquine enantiomers in fatal cerebral malaria. Int J Clin Pharmacol Ther 1999, 37:58-6I. Erratum in: Int J Clin Pharmacol Ther 1999, 37:316

31. Riffkin CD, Chung R, Wall DM, Zalcberg JR, Cowman AF, Foley M, Tilley L: Modulation of the function of human MDR I P-glycoprotein by the antimalarial drug mefloquine. Biochem Pharmacol 1996, 52:1545-I552.

32. Pussard $E$, Merzouk M, Barennes $H$ : Increased uptake of quinine into the brain by inhibition of P-glycoprotein. Eur J Pharm Sci 2007, 32:123-127.

33. Aarnoudse AL, van Schaik RH, Dieleman J, Molokhia M, van Riemsdijk MM, Ligthelm RJ, Overbosch D, Heiden IP van der, Stricker BH: MDRI gene polymorphisms are associated with neuropsy- 
chiatric adverse effects of mefloquine. Clin Pharmacol Ther 2006, 80:367-374.

34. Karbwang J, White NJ: Clinical pharmacokinetics of mefloquine. Clin Pharmacokinet 1990, 19:264-279.

35. Jones R, Kunsman G, Levine B, Smith M, Stahl C: Mefloquine distribution in postmortem cases. For Sci Int 1994, 68:29-32.

36. van Riemsdijk MM, Ditters JM, Sturkenboom MC, Tulen JH, Ligthelm RJ, Overbosch D, Stricker BH: Neuropsychiatric events during prophylactic use of mefloquine before travelling. Eur J Clin Pharmacol 2002, 58:44|-445.

37. Kielian T: Glial connexins and gap junctions in CNS inflammation and disease. I Neurochemistry 2008, 106:1000-1016.

38. Rash JE, Staines WA, Yasumura T, Patel D, Furman CS, Stelmack GL, Nagy Jl: Immunogold evidence that neuronal gap junctions in adult rat brain and spinal cord contain connexin-36 but not connexin-32 or connexin-43. Proc Natl Acad Sci USA 2000, 97:7573-7578.

39. Cummings DM, Yamazaki I, Cepeda C, Paul DL, Levine MS: Neuronal coupling via connexin 36 contributes to spontaneous synaptic currents of striatal medium-sized spiny neurons. J Neurosci Res 2008, 86:2147-2158.

40. Allison DW, Ohran AJ, Stobbs SH, Mameli M, Valenzuela CF, Sudweeks SN, Ray AP, Henriksen SJ, Steffensen SC: Connexin-36 gap junctions mediate electrical coupling between ventral tegmental area GABA neurons. Synapse 2006, 60:20-3I.

4I. Placantonakis DG, Bukovsky AA, Zeng XH, Kiem HP, Welsh JP: Fundamental role of inferior olive connexin 36 in muscle coherence during tremor. Proc Natl Acad Sci USA 2004, 10 I:7 164-7169.

42. Meldrum BS, Rogawski MA: Molecular targets for antiepileptic drug development. Neurotherapeutics 2007, 4:18-6I.

43. Beck $P$, Odle A, Wallace-Huitt $T$, Skinner RD, Garcia-Rill E: Modafinil increases arousal determined by $P I 3$ potential amplitude: an effect blocked by gap junction antagonists. Sleep 2008, 31:1647-1654.

44. Kälviäinen R, Khyuppenen J, Koskenkorva P, Eriksson K, Vanninen R, Mervaala E: Clinical picture of EPMI-Unverricht-Lundborg disease. Epilepsia 2008, 49:549-556.

45. Joensuu T, Lehesjoki AE, Kopra O: Molecular background of EPMI-Unverricht-Lundborg disease. Epilepsia 2008, 49:557-563.

46. Abrahamson M, Alvarez-Fernandez M, Nathanson CM: Cystatins. Biochem Soc Symp 2003:179-199.

47. Pennacchio LA, Bouley DM, Higgins KM, Scott MP, Noebels JL, Myers RM: Progressive ataxia, myoclonic epilepsy and cerebellar apoptosis in cystatin B-deficient mice. Nat Genet 1998, 20:25I-258.

48. Lieuallen K, Pennacchio LA, Park M, Myers RM, Lennon GG: Cystatin B-deficient mice have increased expression of apoptosis and glial activation genes. Hum Mol Genet 200I, 10:1867-187I.

49. Shannon P, Pennacchio LA, Houseweart MK, Minassian BA, Myers RM: Neuropathological changes in a mouse model of progressive myoclonus epilepsy: cystatin B deficiency and Unverricht-Lundborg disease. I Neuropathol Exp Neurol 2002, 61:1085-1091.

50. Franceschetti S, Sancini G, Buzzi A, Zucchini S, Paradiso B, Magnaghi G, Frassoni C, Chikhladze M, Avanzini G, Simonato M: A pathogenetic hypothesis of Unverricht-Lundborg disease onset and progression. Neurobiol Dis 2007, 25:675-685.

5I. Kaasik A, Kuum M, Aonurum A, Kalda A, Vaarmann A, Zharkovsky A: Seizures, ataxia, and neuronal loss in cystatin B heterozygous mice. Epilepsia 2007, 48:752-757.

52. Farahani R, Pina-Benabou MH, Kyrozis A, Siddiq A, Barradas PC, Chiu FC, Cavalcante LA, Lai JC, Stanton PK, Rozental R: Alterations in metabolism and gap junction expression may determine the role of astrocytes as "good samaritans" or executioners. Glia 2005, 50:35I-36I.

53. Amabeoku G], Farmer CC: Gamma-aminobutyric acid and mefloquine-induced seizures in mice. Prog Neuropsychopharmacol Biol Psychiatry 2005, 29:917-921.

54. Department of the Army Office of the Surgeon General. Memorandum. Subject: Updated Guidance on Use of Mefloquine $\left(\right.$ Lariam $\left.^{\circledR}\right)$ for Malaria Prophylaxis, 2 February 2009 [http://www.pdhealth.mil/downloads/DASG Memorandum.pdf]

55. Toovey S: Mefloquine neurotoxicity: A literature review. Travel Med Infect Dis 2009, 7:2-6.
Publish with Biomed Central and every scientist can read your work free of charge

"BioMed Central will be the most significant development for disseminating the results of biomedical research in our lifetime. "

Sir Paul Nurse, Cancer Research UK

Your research papers will be:

- available free of charge to the entire biomedical community

- peer reviewed and published immediately upon acceptance

- cited in PubMed and archived on PubMed Central

- yours - you keep the copyright
BioMedcentral 